\title{
Comparison of the pandemic H1N1 2009 experience in the Southern Hemisphere with pandemic expectations
}

\begin{abstract}
Objective: To describe the epidemiological characteristics of the $2009 \mathrm{H} 1 \mathrm{~N} 1$ pandemic virus ( $\mathrm{pH} 1 \mathrm{~N} 1$ ) over the 2009 and 2010 influenza seasons in Australia and New Zealand (NZ) and compare them with expectations based on previous pandemics. Methods: Laboratory-confirmed influenza and influenza-like illness (ILI) data were collected from established general practitioner sentinel surveillance schemes in NZ, Victoria and Western Australia (WA) throughout the 2009 and 2010 winter influenza seasons. Respiratory swabs from a sample of ILI patients were tested for influenza type and subtype. ILI rates and laboratory-confirmed influenza data were analysed by age group and over time. Morbidity, mortality and reproductive number data were collated from the published literature.
\end{abstract}

Results: Peak ILI rates and the percentage of influenza-positive swabs from ILI patients from all sentinel surveillance schemes were considerably lower in 2010 than 2009. Compared to the population, cases of ILI were over-represented in the young. While the age distributions in NZ and WA remained consistent, ILI cases were significantly younger in Victoria in 2009 compared to 2010. In Victoria, laboratory-confirmed $\mathrm{pH} 1 \mathrm{~N} 1$ comprised up to $97 \%$ of influenza-positive swabs in 2009 but only $56-87 \%$ in 2010 . Mortality and hospitalisations were lower in 2010. The effective reproduction number $(\mathrm{R})$ for $\mathrm{pH} 1 \mathrm{~N} 1$ was estimated to be 1.2-1.5 in $\mathrm{NZ}$ and WA, similar to estimated $\mathrm{R}$ values for seasonal influenza. Data from the surveillance systems indicated differences in the epidemiology of $\mathrm{pH} 1 \mathrm{~N} 1$ compared to expectations based on previous pandemics. In particular, there was no evidence of a second pandemic wave associated with increased mortality, and complete influenza strain replacement did not occur.

Implications: Pandemic planning needs to accommodate the potential for influenza viruses to produce pandemics of various infectiousness and degrees of severity.

Key words: influenza, surveillance, pandemic Aust NZ J Public Health. 2012; 36:364-8 doi: 10.1111/j.1753-6405.2012.00886.x

\author{
Kristina A. Grant \\ Victorian Infectious Diseases Reference Laboratory, Victoria
}

\section{James E. Fielding}

Victorian Infectious Diseases Reference Laboratory, Victoria; National Centre for Epidemiology and Population Health, The Australian National University, Australian Capital Territory

\section{Geoff N. Mercer}

National Centre for Epidemiology and Population Health, The Australian National University, Australian Capital Territory

\section{Dale Carcione}

Communicable Disease Control Directorate, Department of Health, Western Australia

\section{Lisa Lopez}

Institute of Environmental Science and Research, National Centre for Biosecurity and Infectious Disease, Upper Hutt, New Zealand

\section{David W. Smith}

PathWest Laboratory Medicine Western Australia; School of Biomolecular, Biomedical and Chemical Sciences and School of Pathology and Laboratory Medicine, University of Western Australia

\section{Q. Sue Huang}

Institute of Environmental Science and Research, National Centre for Biosecurity and Infectious Disease, New Zealand

\section{Heath A. Kelly}

Victorian Infectious Diseases Reference Laboratory, Victoria; National Centre for Epidemiology and Population Health, The Australian National University, Australian Capital Territory

1 nfluenza pandemics in the last century - in 1918, 1957 and 1968 - were caused by the influenza A virus subtypes H1N1, H2N2 and $\mathrm{H} 3 \mathrm{~N} 2$ respectively. These pandemics are generally accepted to have been characterised by: successive waves, most marked in the 1918-19 pandemic; a shift in the virus subtype, with subsequent replacement of the previous circulating influenza A strains with the pandemic strain; higher excess mortality, especially in younger age groups, generally associated with a younger age of infection; and an increased reproduction number $(\mathrm{R}$ - the average number of secondary cases infected by one infectious case) ${ }^{1-3}$

Influenza $\mathrm{A}(\mathrm{H} 1 \mathrm{~N} 1)$ virus circulated in humans from 1918 until 1957, reappeared in 1977 and has since co-circulated with the influenza A virus H3N2 subtype. ${ }^{4}$ Influenza A(H1N1)pdm09 (hereafter pH1N1) which arose through a novel reassortment rather than antigenic shift, emerged in North America in 
April 2009, early in the Southern Hemisphere influenza season. There was concurrent out-of-season influenza activity in the Northern Hemisphere, followed by an in-season second wave. ${ }^{5}$

Here, we use influenza-like illness (ILI) and laboratory confirmed pH1N1 infection data from sentinel surveillance systems in New Zealand (NZ) and two Australian States, Victoria and Western Australia (WA), as well as data on hospitalisations, mortality and the effective reproduction number to summarise epidemiological characteristics of the $\mathrm{pH} 1 \mathrm{~N} 1$ virus over two Southern Hemisphere influenza seasons. We compare the results from two Southern Hemisphere countries with expectations based on observations from previous pandemics. ${ }^{1-3}$

\section{Methods}

General practitioner (GP) sentinel surveillance for influenza and influenza-like illness (ILI) is conducted in NZ and Victoria throughout each winter influenza season, usually from May to September, but in 2009 was extended to the end of the year to monitor $\mathrm{pH} 1 \mathrm{~N} 1$. GP sentinel surveillance operates year-round in WA. In NZ, ILI is defined as acute upper respiratory tract infection characterised by abrupt onset and two of the following: fever, chills, headache and myalgia; in Victoria and WA the ILI definition is fever (measured or reported), cough and fatigue. ${ }^{6,7}$

Participating GPs reported weekly consultation rates for ILI, the denominator of which in NZ was the patient population of the practice and, in Victoria and WA, the total number of consultations for that week. Age of all ILI patients was collected by each surveillance system. Proportional age group distributions of ILI cases in 2009 and 2010 and the total State/country population were compared for each surveillance scheme.

Respiratory swabs were collected systematically by participating GPs in NZ from the first ILI patient seen on each Monday, Tuesday and Wednesday, and were tested at the Institute of Environmental Science and Research Limited (ESR) and regional hospital laboratories in Auckland, Waikato and Christchurch. In Victoria and WA combined nose/throat swabs were collected at the GPs' discretion and tested at the Victorian Infectious Diseases Reference Laboratory and PathWest Laboratory Medicine WA, respectively. Swabs were tested by polymerase chain reaction (PCR) at all laboratories in Australia and NZ. All specimens were typed as influenza A or B. Sub-typing was attempted for all specimens; those that could not be sub-typed as influenza A(H1N1) or A(H3N2) were classified as 'untyped'. ${ }^{8-10}$

Data from weeks 18 to 40 (May to September) for both years from the three surveillance schemes were collated and analysed using Microsoft Excel and Stata (version 10.0, StataCorp LP). The chi squared test was used to compare proportions with $p<0.05$ considered statistically significant.

Hospitalisation and mortality data, and estimates of R, were collated from the published literature. ${ }^{11-17}$ We compared surveillance results from our data analysis and the published data on morbidity, mortality and $\mathrm{R}$ with the expectations from previous pandemics as described above. ${ }^{1-3}$

\section{Results}

\section{ILI and laboratory confirmed influenza}

Compared to the high levels in 2009, peak ILI rates from all three sentinel surveillance systems were considerably lower in 2010 (Figure 1). In Victoria and WA, the peak ILI rates in 2010 were low in comparison to previous seasons and approximately one-third of those in 2009: 8.9 versus 23.0 ILI patients per 1000 consultations in Victoria, and 21.1 versus 56.9 patients per 1000 consultations in WA. In NZ the peak ILI rate in 2010 (151.6 per 100,000 population) was similar to previous seasons of high ILI activity in 2003 and 2005 and about half that in 2009 (284.0 per 100,000 population).

The percentage of swabs from ILI patients that were positive for influenza in 2010 was lower than in 2009 for all three surveillance systems (Figure 2). Comparing 2010 to 2009, the percentage positive peaked at $60 \%$ versus $67 \%, 44 \%$ versus $59 \%$ and $44 \%$ versus $91 \%$ in Victoria, WA and NZ respectively.

\section{Hospitalisations and deaths}

Up until mid-October 2010, 732 hospitalisations and 15 confirmed deaths from $\mathrm{pH} 1 \mathrm{~N} 1$ had been reported in NZ, equating to a case fatality risk (CFR) of 8.5 per 100,000, similar to 2009 (9.0 per 100,000). The median age of those who died was higher in 2010 (50 years) than in 2009 (40 years). Hospital admissions in NZ were lower in 2010 (732) compared to $2009(1,122)$. The age distribution of notifications and hospitalisations for $\mathrm{pH} 1 \mathrm{~N} 1$ was similar in 2009 and 2010 in NZ, with highest rates being in children under 5 years ( 80 and 51 per 100,000 population, respectively). ${ }^{6,18}$

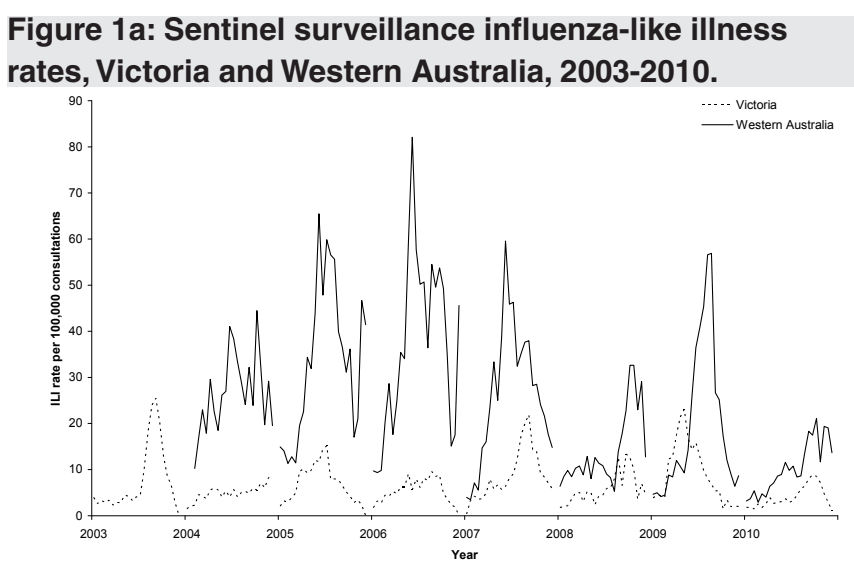

Figure 1b: Sentinel surveillance influenza-like illness rates, New Zealand, 2003-2010.

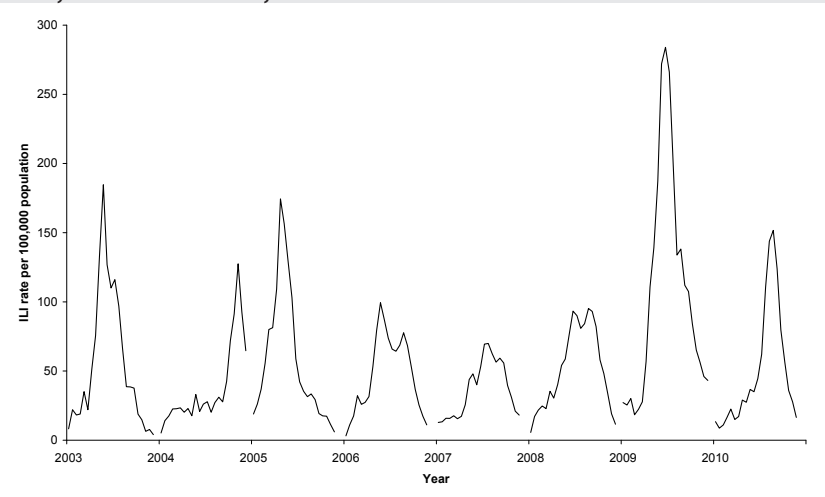


In Australia in 2009 there were 191 confirmed deaths from pH1N1 (median age 53 years) and 4,992 hospitalised cases (median age 31 years). In 2010, there were 22 deaths at a median age of 51 years. ${ }^{12}$ Estimates of the CFR were not available for either year. We could find no published data on hospitalisations in 2010 for Australia.

\section{Age distribution}

Compared to the population distributions of the age group categories, those aged 0-19 years were significantly over-represented in the ILI cases in NZ, Victoria and WA in 2009 ( $p<0.001$ for all surveillance schemes). This trend continued in 2010 for both the $\mathrm{NZ}$ and WA surveillance schemes, with no significant difference to the age distributions observed in 2009 ( $p=0.35$ in NZ and $p=0.14$ in WA). In contrast, ILI cases in Victoria were significantly younger in 2009 compared to $2010(p<0.001)$ (Figure 3 ).

The majority of confirmed pH1N1 cases in 2010 were in the 5-19 and 20-49 age groups (Table 1).

The median ages of those with confirmed $\mathrm{pH} 1 \mathrm{~N} 1$ infection were 24, 26 and 17 years in NZ, Victoria and WA respectively. Although there were low numbers of H3N2 detections, the median ages of those infected were higher than for those infected with $\mathrm{pH} 1 \mathrm{~N} 1$ in NZ (46 years) and WA (36 years) but not in Victoria (18 years). The median age of those infected with type B influenza (4, 12 and 11 years in NZ, WA and Victoria respectively) was lower than for influenza A (Table 1).

\section{Strain circulation}

As had been the case in all surveillance schemes in 2009, ${ }^{19-21} \mathrm{pH} 1 \mathrm{~N} 1$ was the most commonly identified strain in 2010, particularly in Victoria and NZ ( $87 \%$ and $76 \%$ of tested swabs respectively) (Table 1). Compared to the other surveillance schemes, a significantly higher proportion of influenza positive swabs $(40 \%, p<0.001)$ in WA in 2010 were type B, of which 59\% were detected in the 5-19 year old age group. There were no detections of the previous seasonal H1N1 virus from any surveillance scheme. Influenza A (H3N2) was detected in relatively low numbers in 2010 in all surveillance schemes.

\section{Reproduction number}

The effective reproduction number was estimated using a stochastic version of a standard susceptible-infected-removed (SIR) model with Bayesian inference and accounted for the effect of imported cases. ${ }^{13}$ The mean effective reproduction number (R) during the peak of transmission was estimated for pH1N1 in 2009 WA as 1.2-1.4 ${ }^{13}$ and for NZ as 1.2-1.5, ${ }^{14-16}$ although earlier estimates of a higher R had also been reported in NZ. ${ }^{16,17}$ In NZ and WA the estimated effective reproduction number was initially around 1.6-2.0, but rapidly declined to 1.2-1.4. This early higher estimate is expected from the nature of the estimation procedure and is not indicative of the population-wide reproduction number in the early stages of the outbreak. ${ }^{16,22}$ It was not possible to estimate an unbiased R for Victoria because of undetected early transmission of $\mathrm{pH} 1 \mathrm{~N} 1$ prior to testing. ${ }^{13}$

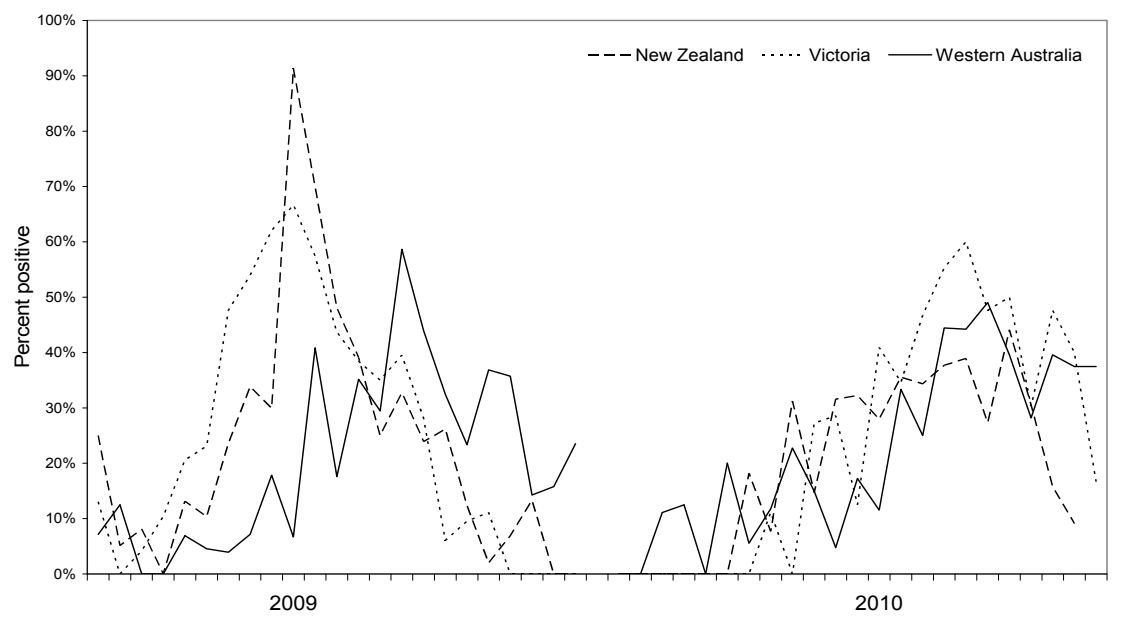

Figure 2: Percentage of sentinel surveillance swabs positive for influenza by week and surveillance scheme, 2009-2010.

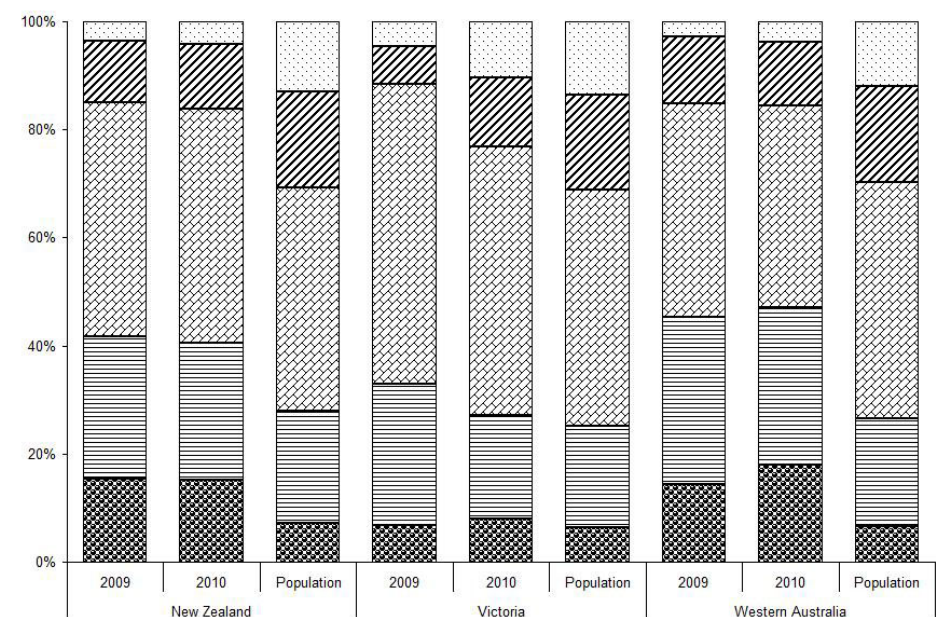

Figure 3: Proportional age distribution of sentinel surveillance influenza-like illness cases and total population by surveillance scheme, 2009-2010.
$\square 65+$
$\square 50-64$
ه 20-49
目 $5-19$
$0-4$ 


\section{Comparison with pandemic expectations}

The differences between observations from 2009-10 in Australia and NZ, and expectations based on previous pandemics, are summarised in Table 2. Evidence from the three surveillance systems in the Southern Hemisphere shows that pH1N1 differed substantially from pandemic expectations. It did not cause a second pandemic wave associated with increased mortality. It replaced the previous H1N1 seasonal influenza subtype, but did not replace the H3N2 subtype. It was not associated with a higher reproduction number and, although there was increased mortality in younger age groups, overall laboratory-confirmed mortality was lower than the excess mortality modelled to occur with seasonal influenza. These two measures are not strictly comparable and capture of all laboratoryconfirmed deaths was likely to have been incomplete.

While previous influenza pandemics have been caused by antigenic shift in the influenza subtype, leading to higher rates of infection in a naïve population, $\mathrm{pH} 1 \mathrm{~N} 1$ was characterised by a novel reassortant. In previous pandemics, all influenza A viruses were replaced by the pandemic strain, ${ }^{2}$ whereas in 2009 and 2010 influenza $\mathrm{A}(\mathrm{H} 3 \mathrm{~N} 2)$ continued to circulate, albeit at low levels, and only the seasonal H1N1 strain was replaced by pH1N1.

\section{Discussion}

Data from three sentinel surveillance systems highlight the importance of using a variety of information sources to describe the epidemiology of influenza. We found differences in the ILI rates across the three surveillance schemes, which may be subject to local influences, such as media, differences in the way surveillance is conducted or targeted vaccination programs. These differences may also reflect real differences in viral circulation or, most likely, a combination of these factors. However, data on laboratoryconfirmed influenza, assessed by the percentage of respiratory swabs positive for influenza, showed that the seasons of 2009 and 2010 were generally consistent between the three surveillance schemes in terms of timing and relative magnitude of the influenza epidemics. The higher number of tests for influenza in 2009 was most likely due to increased testing caused by increased concern about $\mathrm{pH} 1 \mathrm{~N} 1$ and targeted testing of patients, for example, those who were quarantined pending a negative laboratory result. Examining the proportion of swabs that test positive for influenza is an informative way to adjust for different testing practices between jurisdictions..$^{23}$

The most plausible explanations for differential levels of ILI activity in 2010 recorded by the three surveillance systems are: early arrival of pH1N1 into Victoria and subsequent spread of the virus before interventions had commenced; ${ }^{13}$ high $\mathrm{pH} 1 \mathrm{~N} 1$ infection rates in both Australia and NZ during the first pandemic season; ${ }^{9,24}$ geographic variation in the reach of pH1N1 in NZ in 2009;,69 and limited antigenic drift of the $\mathrm{pH} 1 \mathrm{~N} 1$ virus. ${ }^{1,25}$ The role of population immunity and benefits from the vaccination programs in lower ILI activity hospital admissions and deaths in 2010 are less clear because complete vaccination coverage data from both the 2009 monovalent pandemic vaccine program (funded for all Australians but only for health care workers in NZ) and the 2010 trivalent seasonal vaccine are not available for comparison in both countries.

The effective reproduction number for $\mathrm{pH} 1 \mathrm{~N} 1$ was likely to have been in the range 1.2-1.5, similar to seasonal influenza and lower than previous pandemics. Values in the range 1.2-1.4 are consistent with estimates of $\mathrm{R}$ obtained from seroprevalence surveys of $\mathrm{pH} 1 \mathrm{~N} 1 .^{26,27} \mathrm{R}$ has been estimated to be 2.0 (with a range of 1.4-2.8) for the 1918 pandemic, 1.6 for the pandemic of 1957 and 1.8 for the 1968 pandemic. R varies year-to-year for seasonal influenza with a mean around 1.3 and a range of $0.9-2.1 .^{2,28-30}$

While a shift in distribution to the younger age groups is a distinctive feature of pandemics, it is possible that the younger age

Table 2. Comparison of pandemic expectations with observations from Australia and New Zealand 2009-10.

\section{Pandemic expectation}

Sometimes multiple waves

Possibility of second wave with an increase in mortality and morbidity

Pandemic strain resulted from an antigenic shift

Increased mortality overall with case fatality risk up to $2 \%$

Increased morbidity and mortality in younger people Younger age of infection

All influenza $A$ viruses replaced by pandemic strain

$R$ mean: 2.0; range: 1.4-2.8 29,30
Evidence from the pH1N1 pandemic in Australia and NZ Seasonal waves

Decrease in mortality and morbidity in second season

Pandemic strain resulted from a novel reassortant of a circulating subtype $^{36}$

Probable decreased mortality overall with case fatality risk $<0.01 \%$

Increased morbidity and mortality in younger people

Younger age of infection (possibly an $\mathrm{H} 1 \mathrm{~N} 1$ characteristic)

$A(H 1 N 1)$ replaced only; $A(H 3 N 2)$ continues to circulate

$\mathrm{R}=1.2-1.5^{13-17,26,27}$

Table 1: Sentinel surveillance swabs positive for influenza by surveillance scheme, type/subtype and age group, 2010.

\begin{tabular}{|c|c|c|c|c|c|c|c|c|c|c|c|c|}
\hline \multirow{3}{*}{$\begin{array}{l}\text { Age group } \\
\text { (years) }\end{array}$} & \multicolumn{4}{|c|}{ NZ } & \multicolumn{4}{|c|}{ Victoria } & \multicolumn{4}{|c|}{ WA } \\
\hline & \multicolumn{3}{|c|}{ Flu A n (\%) } & \multirow{2}{*}{$\begin{array}{c}\text { Flu B n } \\
(\%)\end{array}$} & \multicolumn{3}{|c|}{ Flu A n (\%) } & \multirow{2}{*}{$\begin{array}{c}\text { Flu B n } \\
(\%)\end{array}$} & \multicolumn{3}{|c|}{ Flu A n (\%) } & \multirow{2}{*}{$\begin{array}{c}\text { Flu B n } \\
(\%)\end{array}$} \\
\hline & $\mathrm{pH} 1 \mathrm{~N} 1$ & $\mathrm{H} 3$ & Untyped & & $\mathrm{pH} 1 \mathrm{~N} 1$ & $\mathrm{H} 3$ & Untyped & & $\mathrm{pH} 1 \mathrm{~N} 1$ & $\mathrm{H} 3$ & Untyped & \\
\hline $0-4$ & $23(8)$ & $0(0)$ & $4(5)$ & $1(100)$ & $6(4)$ & $1(14)$ & $1(9)$ & $0(0)$ & $6(6)$ & $0(0)$ & $0(0)$ & $10(14)$ \\
\hline $5-19$ & $87(32)$ & $0(0)$ & $19(23)$ & $0(0)$ & $49(33)$ & $3(43)$ & $2(18)$ & $3(60)$ & $47(47)$ & $1(14)$ & $0(0)$ & $42(59)$ \\
\hline $20-49$ & $131(48)$ & $2(67)$ & $50(40)$ & $0(0)$ & $78(52)$ & $3(43)$ & $7(64)$ & $2(40)$ & $43(43)$ & $4(57)$ & $0(0)$ & $17(24)$ \\
\hline $50-64$ & $31(11)$ & $1(33)$ & $9(20)$ & $0(0)$ & $16(11)$ & $0(0)$ & $1(9)$ & $0(0)$ & $4(4)$ & $1(14)$ & $0(0)$ & $1(1)$ \\
\hline $65+$ & $2(1)$ & $0(0)$ & $1(11)$ & $0(0)$ & $0(0)$ & $0(0)$ & $0(0)$ & $0(0)$ & $1(1)$ & $1(14)$ & $0(0)$ & $1(1)$ \\
\hline Total & $274(76)$ & $3(1)$ & $83(23)$ & $1(0.3)$ & $149(87)$ & $7(4)$ & $11(6)$ & $5(3)$ & $101(56)$ & $7(4)$ & $0(0)$ & $71(40)$ \\
\hline Median Age & 24 & 46 & 27 & 4 & 26 & 18 & 34 & 12 & 17 & 36 & - & 11 \\
\hline
\end{tabular}


of infection of $\mathrm{pH} 1 \mathrm{~N} 1$ in both years is due to the younger age of infection of characteristic of influenza $\mathrm{A}(\mathrm{H} 1 \mathrm{~N} 1)$ viruses. ${ }^{31,32}$ The age of infection tends to increase in the years following pandemics. There was a suggestion of this trend in the median age of ILI infections in Victoria in 2010, but not in WA or NZ.

In summary, the pandemic caused by $\mathrm{pH} 1 \mathrm{~N} 1$ was very different to pandemic expectations, many of which informed pandemic planning in Australia and around the world. Early recognition of these differences may partly explain the public and professional disquiet about Australia's response to the pandemic. ${ }^{33,34}$ Recognition of the full range of the potential for influenza viruses to produce pandemics of various infectiousness (roughly measured by R), and degrees of severity (roughly measured by the risk of hospitalisation and death), reinforces the call for revised pandemic planning to accommodate plans that are calibrated on both spread and severity. ${ }^{35}$

\section{Acknowledgements}

We gratefully acknowledge the contribution of the patients, general practitioners and practice staff, and the public health unit co-ordinators involved in the sentinel surveillance schemes. We thank the laboratory staff responsible for influenza virus detection. Influenza surveillance in NZ is funded by the Ministry of Health. The State Health Departments support influenza surveillance in Victoria and Western Australia. Kristina A. Grant and James E. Fielding contributed equally to this paper.

\section{References}

1. Ferguson NM, Galvani AP, Bush RM. Ecological and immunological determinants of influenza evolution. Nature. 2003;422(6930):428-33.

2. Miller MA, Viboud C, Balinska M, Simonsen L. The Signature Features of Influenza Pandemics - Implications for Policy. N Engl J Med. 2009;360:2595-8.

3. Simonsen L, Olsen DR, Viboud C, et al. Pandemic influenza and mortality: past evidence and projection for the future. In: Knobler SL MA, Mahmoud A, Lemon SM, editors. The Threat of Pandemic Influenza: Are We Ready? Washington (DC): National Academies Press; 2005. p. 89-114.

4. Garten RJ, Davis CT, Russell CA, Shu B, Lindstrom S, Balish A, et al. Antigenic and genetic characteristics of swine-origin 2009 A(H1N1) influenza viruses circulating in humans. Science. 2009;325(5937):197-201.

5. World Health Organization. Global Alert and Response (GAR) - Pandemic (HIN1) 2009 [Internet]. Geneva (CHE): WHO; 2012 [cited 2010 Nov 24]. Available from: http://www.who.int/csr/disease/swineflu/en/index.html

6. Bandaranayake D, Jacobs M, Baker M, Hunt D, Wood T, Bissielo A, et al. The second wave of 2009 pandemic influenza A(H1N1) in New Zealand, JanuaryOctober 2010. Euro Surveill. 2011;16(6):14-24.

7. Thursky K, Cordova SP, Smith D, Kelly H. Working towards a simple case definition for influenza surveillance. J Clin Virol. 2003;27(2):170-9.

8. Chidlow G, Harnett G, Williams S, Levy A, Speers D, Smith DW. Duplex realtime reverse transcriptase PCR assays for rapid detection and identification of pandemic (H1N1) 2009 and seasonal influenza A/H1, A/H3, and B viruses. $J$ Clin Microbiol. 2010;48(3):862-6.

9. Bandaranayake D, Huang QS, Bissielo A, Wood T, Mackereth G, Baker MG, et al. Risk factors and immunity in a nationally representative population following the 2009 influenza A(H1N1) pandemic. PLoS One. 2010;5(10):e13211.

10. Fielding J, Higgins N, Gregory J, Grant K, Catton M, Bergeri I, et al. Pandemic H1N1 influenza surveillance in Victoria, Australia, April-September, 2009. Euro Surveill. 2009;14(42):37-44.

11. Lopez L, Huang S. Influenza in New Zealand 2009 [Internet]. Wellington (NZ): New Zealand Ministry of Health; 2010 [cited 2010 Nov 30]. Available from: http://www.surv.esr.cri.nz/PDF_surveillance/Virology/FluAnnRpt/ InfluenzaAnn2009.pdf

12. Department of Health and Ageing. Australian Influenza Surveillance Report No.44, 2010, Rreporting Period: 30 October - 5 November 2010 [Internet]. Canberra (AUST): Commonwealth of Australia; 2010 [cited 2011 Mar 16]. Available from: http://www.health.gov.au/internet/main/publishing.nsf/Content/ cda-ozflu-no44-10.htm/\$File/ozflu-no44-2010.pdf
13. Kelly HA, Mercer GN, Fielding JE, Dowse GK, Glass K, Carcione D, et al. Pandemic (H1N1) 2009 influenza community transmission was established in one Australian state when the virus was first identified in North America. PLoS One. 2010;5(6):e11341. PubMed PMID: 20596536.

14. Paine S, Mercer GN, Kelly PM, Bandaranayake D, Baker MG, Huang QS, et al. Transmissibility of 2009 pandemic influenza A(H1N1) in New Zealand: effective reproduction number and influence of age, ethnicity and importations. Euro Surveill. 2010;15(24):9-17.

15. Hsieh YH. Pandemic influenza A (H1N1) during winter influenza season in the southern hemisphere. Influenza Other Respi Viruses. 2010;4(4):187-97.

16. Roberts MG, Nishiura H. Early estimation of the reproduction number in the presence of imported cases: pandemic influenza H1N1-2009 in New Zealand. PLoS One. 2011;6(5):e17835. PubMed PMID: 21637342.

17. Nishiura H, Wilson N, Baker MG. Estimating the reproduction number of the novel influenza A virus (H1N1) in a Southern Hemisphere setting: preliminary estimate in New Zealand. N Z Med J. 2009;122(1299):73-7.

18. Lopez L, Bandaranayake D, Huang S. Influenza in New Zealand 2010 [Internet]. Wellington (NZ): New Zealand Ministry of Health; 2011 [cited 2011 Mar 11]. Available from: http://www.surv.esr.cri.nz/PDF_surveillance/Virology/ FluAnnRpt/InfluenzaAnn2010.pdf

19. Kelly HA, Grant KA, Fielding JE, Carville KS, Looker CO, Tran T, et al. Pandemic influenza H1N1 2009 infection in Victoria, Australia: No evidence for harm or benefit following receipt of seasonal influenza vaccine in 2009 . Vaccine. 2011;29(37):6419-26.

20. Dowse GK, Smith DW, Kelly H, Barr I, Laurie KL, Jones AR, et al. Incidence of pandemic (H1N1) 2009 influenza infection in children and pregnant women during the 2009 influenza season in Western Australia - a seroprevalence study. Med J Aust. 2011;194(2):68-72.

21. Baker MG, Wilson N, Huang QS, Paine S, Lopez L, Bandaranayake D, et al. Pandemic influenza A(H1N1)v in New Zealand: the experience from April to August 2009. Euro Surveill. 2009;14(34):6-11.

22. Mercer GN, Glass K, Becker NG. Effective reproduction numbers are commonly overestimated early in a disease outbreak. Stat Med. 2011;30(9):984-94.

23. Lambert SB, Faux CE, Grant KA, Williams SH, Bletchly C, Catton MG, et al. Influenza surveillance in Australia: we need to do more than count. Med J Aust. 2010;193(1):43-5.

24. Dowse GK, Effler P, Kelly HA, Smith DW, Barr I, Laurie K, et al. Incidence of pandemic influenza (H1N1) 2009 infection in children and pregnant women during the 2009 influenza season in Western Australia - estimates from a seroprevalence study. Med J Aust. 2011;194(2):68-72.

25. Barr IG, Cui L, Komadina N, Lee RT, Lin RT, Deng Y, et al. A new pandemic influenza $\mathrm{A}(\mathrm{H} 1 \mathrm{~N} 1)$ genetic variant predominated in the winter 2010 influenza season in Australia, New Zealand and Singapore. Euro Surveill. 2010; 15(42):6-11.

26. Nishiura H, Chowell G, Castillo-Chavez C. Did modeling overestimate the transmission potential of pandemic (h1n1-2009)? Sample size estimation for post-epidemic seroepidemiological studies. PLoS One. 2011;6(3):e17908. doi:10.1371/journal.pone.0017908.

27. Glass K, Kelly H, Mercer GN. Pandemic influenza H1N1: Reconciling serosurvey data with estimates of the reproduction number. Epidemiology. Forthcoming 2011.

28. Chowell G, Nishiura H, Bettencourt LM. Comparative estimation of the reproduction number for pandemic influenza from daily case notification data. $J R$ Soc Interface. 2007;4(12):155-66.

29. Viboud C, Tam T, Fleming D, Handel A, Miller MA, Simonsen L. Transmissibility and mortality impact of epidemic and pandemic influenza, with emphasis on the unusually deadly 1951 epidemic. Vaccine. 2006;24(4446):6701-7.

30. Coburn BJ, Wagner GB, Blower S. Modelling influenza epidemics and pandemics: insights into the future of swine flu (H1N1). BMC Med. 2009; 7:30.

31. Kelly H, Grant K, Williams S, Smith D. The median age of patients infected with H1N1 swine-origin influenza 2009 in the United States and H1N1 seasonal influenza 2007-8 in Australia. Influenza Other Respi Viruses. 2009;3(4):183-8.

32. Kelly HA, Grant KA, Williams S, Fielding J, Smith D. Epidemiological characteristics of pandemic influenza H1N1 2009 and seasonal influenza infection. Med J Aust. 2009;191(3):146-9.

33. Kelly $\mathrm{H}$. A pandemic response to a disease of predominantly seasonal intensity Med J Aust. 2009;192(2):81-3.

34. Eizenberg P. The general practice experience of the swine flu epidemic in Victoria - lessons from the front line. Med J Aust. 2009;191(3):151-3.

35. Kelly HA, Priest PC, Mercer GN, Dowse GK. We should not be complacent about our population-based public health response to the first influenza pandemic of the 21st century. BMC Public Health. 2011;11:78.

36. Trifonov V, Khiabanian H, Greenbaum B, Rabadan R. The origin of the recent swine influenza A(H1N1) virus infecting humans. Euro Surveill. 2009;14(17):6. 